\title{
Renal Artery Disease
}

National Cancer Institute

\section{Source}

National Cancer Institute. Renal Artery Disease. NCI Thesaurus. Code C101254.

Pathology involving the main renal arteries or extrarenal arterial branches. (ACC) 